\title{
Methanotrophs used in Fruit and Vegetable Preservation
}

\author{
Li Chunyu \\ Key Laboratory for Food Science and \\ Engineering, Harbin University of Commerce \\ Harbin, China \\ 2211034032@qq.com \\ Gao Shengbo \\ Key Laboratory for Food Science and \\ Engineering, Harbin University of Commerce \\ Harbin, China \\ 544546692@qq.com
}

\author{
Zhang Jianxiong \\ Key Laboratory for Food Science and \\ Engineering, Harbin University of Commerce \\ Harbin, China
}

\author{
Xin Jiaying* \\ Key Laboratory for Food Science and \\ Engineering Harbin University of Commerce \\ Harbin, China \\ xinjiayingvip@163.com \\ * Corresponding Authr
}

Keywords: Methanotrophs; $\mathrm{MMO}$; Catalyze; Ethylene; Epoxidation

\begin{abstract}
Methanotrophs are a group of microbes with methane as the sole carbon and energy source. Methane Monooxygenase (MMO) is the vital enzyme system in the metabolic process of methanotrophs. Under the action of molecular dioxygen, MMO can catalyze olefin epoxidation reaction. Fruits and vegetables can release ethylene in the storage process, which improving the respiratory intensity of fruit and improving the oxygen permeability of fruit tissue protoplasm, and promoting the fruit respiration and other biochemical processes with oxygen. In this paper, changing the culture conditions can improve the ability of MMO in methanotrophs catalyzed ethylene epoxidation into oxirane. The preservation of fruits and vegetables can apply it. Adding vitamin B12 can increase the activity of MMO. The optimum concentration is $8 \mathrm{mg} / \mathrm{L}$. Exogenous electron donor sodium formate can improve the epoxidation capacity of MMO by providing the NADH and making the epoxidation continuous. The optimum concentration of sodium formate is $20 \mathrm{mmol} / \mathrm{L}$. In the study,p hosphate can improve the permeability of methanotrophs cells, which increasing the exposure of ethylene to MMO. The reaction rate can be improved. The optimal concentration of phosphate is $10 \mathrm{mmol} / \mathrm{L}$. When the three kinds of substances are in the optimum concentration, MMO may have the highest activity in epoxidation.
\end{abstract}

\section{Introduction}

Methane-oxidizing bacteria (methanotrophs) is the branches of methyl oxidation bacteria[1]. It is a kind of gram-negative bacteria, which can directly use methane as carbon and energy sources. The complete cell of methane-oxidizing bacteria contains MMO enzyme and methanol dehydrogenase (MDH). MMO can catalyze methane into methanol, and MDH can oxidize methanol to formaldehyde. Ultimately the reaction brings carbon dioxide and a large number of NADH. In addition, Romanovskaia and other researchers have found that methane-oxidizing bacteria can also be used for the production of ethanol[2]. Ethylene is a compound of plant hormone. The studies have found that all plants can produce ethylene. It is related to the ripening of the fruits and vegetables. In the respiration process of fruits and vegetables, they breathe in oxygen and release carbon dioxide, which cause to produce ethylene and make water decrease.Then ethylene can activate respiratory and stimulate the normal maturation of fruit[3]. However, only in the low concentration of ethylene gas, it can play a positive role. The high concentration ethylene can increase the respiration intensity of fruits and vegetables, which will result in the softening of fruits and vegetables, the decline of the nutritional 
value and the shortening the life of fruits and vegetables[4].Therefore, it is very important to control the concentration of ethylene in the preservation process of fruits and vegetables.

Methane monooxygenase (MMO) is a catalyst which can catalyze the oxidation of methane to methanol. MMO can also catalyze another reaction-- ethylene epoxidation reaction. In this reaction, ethylene can be epoxidized into oxirane. Ethylene as a ripening agent of fruits and vegetables, it's content should be reduced in the storage environment. In this paper, we focus on the improvement of ethylene epoxidation activity of the MMO. The effect of the addition of exogenous electron donor sodium formate, vitamin B12 and phosphate on the MMO activity have been studied. Different concentrations of sodium formate, phosphate and vitamin B12 have been added and Gas Chromatography has been used to determine the epoxyethane-producting capacity of methaneoxidizing bacteria under the addition of formate, phosphate and vitamin B12.

\section{Materials and Methods}

Chemicals and Materials. Sodium formate, NaH2PO4 and vitamin B12 are obtained from Sinopharm Chemical Reagent Co. Ltd. (Shanghai, China). All stock solution were prepared daily with distilled water.

Methylosinus trichosporium 3011 was obtained from the Institute of Microbiology and Virology (Kiev. Ukraine)[5]

Methylosinus Trichosporium IMV3011 Culture. Methylosinus trichosporium IMV3011 was maintained on mineral salt agar plates in a desiccator jar under an initial atmosphere of methane and air $(1: 10, \mathrm{~V} / \mathrm{V})$ at $30^{\circ} \mathrm{C}$. Cultures were transferred every 4 weeks. To prepare an inoculum for batch cultivation studies, $5 \mathrm{ml}$ of mineral salt medium was added to a 5-day-old agar plates; the agar plates was washed briefly to resuspend the cells, and the liquid was transferred to a $250 \mathrm{ml}$ closed flask containing $50 \mathrm{ml}$ of mineral salt medium. Cultures were grown on methane and air $(1: 10, \mathrm{~V} / \mathrm{V})$ at $30^{\circ} \mathrm{C}$ with shaking $(150 \mathrm{rpm})$. The gas phase of the bottle was refreshed by a gas mixture of methane and air $(1: 1, \mathrm{~V} / \mathrm{V})$ every $24 \mathrm{~h}$. The following mineral salt was used for cultivation, $(\mathrm{g} / \mathrm{L}): \mathrm{NH} 4 \mathrm{Cl}, 0.5$; K2HPO4, 0.49; KH2PO4•7H2O, 0.40; $\mathrm{MgSO} 4 \cdot 7 \mathrm{H} 2 \mathrm{O}, 0.3 ; \mathrm{CaCl} 2 \cdot 2 \mathrm{H} 2 \mathrm{O}, 0.02 ; \mathrm{KNO} 3,1.6 ; \mathrm{NaCl}, 0.3$; FeSO4•7H2O, 0.004; $\mathrm{CuSO} 4 \cdot 5 \mathrm{H} 2 \mathrm{O}, \quad 0.004 ; \mathrm{MnSO} 4 \cdot \mathrm{H} 2 \mathrm{O}, 0004 ; \mathrm{ZnSO} 4 \cdot 7 \mathrm{H} 2 \mathrm{O}, 0.00034$; $\mathrm{Na} 2 \mathrm{MoO} 4 \cdot 2 \mathrm{H} 2 \mathrm{O}, 0.00024 ; \mathrm{pH}$ 7.0. Cells were harvested after $96 \mathrm{~h}$ cultivation by centrifugation at $10,000 \mathrm{~g}$ for $10 \mathrm{~min}$ and washed twice with fresh mineral salt medium. Cells were resuspended in the same mineral salt medium and used for the experiment.

Standard Curve of Epoxyethane. Take $1 \mathrm{~mL}$ standard epoxyethane and set the volume to $1000 \mathrm{~mL}$. Epoxyethane's density is $0.8711 \mathrm{~g} / \mathrm{cm} 3$. The concentration of epoxyethane was $20 \mathrm{mmol} / \mathrm{L}$. Then take $5 \mathrm{~mL}, 10 \mathrm{~mL}, 15 \mathrm{~mL}, 20 \mathrm{~mL}, 25 \mathrm{~mL}, 30 \mathrm{~mL}$ from the liquid into 6 volumetric flasks of $200 \mathrm{~mL}$ separately and set the volume to $200 \mathrm{~mL}$. The concentration of epoxyethane was $0.5 \mathrm{mmol} / \mathrm{L}$, $1.0 \mathrm{mmol} / \mathrm{L}, 1.5 \mathrm{mmol} / \mathrm{L}, 2.0 \mathrm{mmol} / \mathrm{L}, 2.5 \mathrm{mmol} / \mathrm{L}, 3.0 \mathrm{mmol} / \mathrm{L}$. One microliter liquid was taken by the micro sampler, and the Gas Chromatography analysis was carried out.

The Effect of Sodium Formate on Ethylene Epoxidative Activity of MMO. Take 1mL a 4day-old bacteria into 18 ampoule bottles separately and add $1 \mathrm{~mL}$ sodium formate solution whose concentration was $10 \mathrm{mmol} / \mathrm{L}, 20 \mathrm{mmol} / \mathrm{L}, 40 \mathrm{mmol} / \mathrm{L}, 60 \mathrm{mmol} / \mathrm{L}, 80 \mathrm{mmol} / \mathrm{L}$ respectively. Three parallel samples, and three blank groups were used as the contrast. Four milliliters ethylene was injected to 18 bottles separately. Then the bottles were put into the shaker and were oscillated for $30 \mathrm{~min}$. The supernatant was harvested by centrifugation at $12,000 \mathrm{~g}$ for $15 \mathrm{~min}$ and $1 \mathrm{uL}$ liquid was taken by the micro sampler, and the Gas Chromatography analysis was carried out for 3 times.

The effect of Phosphate on ethylene epoxidative activity of MMO

Take $1 \mathrm{~mL}$ a 4-day-old bacteria into 18 ampoule bottles separately and add $1 \mathrm{~mL}$ phosphate solution whose concentration was $5 \mathrm{mmol} / \mathrm{L}, 10 \mathrm{mmol} / \mathrm{L}, 15 \mathrm{mmol} /, 20 \mathrm{mmol} / \mathrm{L}, 25 \mathrm{mmol} / \mathrm{L}$ respectively. Three parallel samples, and three blank groups were used as the contrast. Four milliliters ethylene was injected to 18 bottles separately. Then the bottles were put into the shaker and was oscillated for 
$30 \mathrm{~min}$. The supernatant was harvested by centrifugation at $12,000 \mathrm{~g}$ for $15 \mathrm{~min}$ and. $1 \mathrm{uL}$ liquid was taken by the micro sampler, and the Gas Chromatography analysis was carried out for 3 times.

The effect of Vitamin B12 on ethylene epoxidative activity of MMO

Take $1 \mathrm{~mL}$ f a 4-day-old bacteria into 18 ampoule bottles separately and add $1 \mathrm{~mL}$ vitamin B12 solution whose concentration was $4 \mathrm{mmol} / \mathrm{L}, 8 \mathrm{mmol} / \mathrm{L}, 16 \mathrm{mmol} / \mathrm{L}, 24 \mathrm{mmol} / \mathrm{L}, 32 \mathrm{mmol} / \mathrm{L}$ respectively. Three parallel samples, and three blank groups were used as the contrast. Four milliliters ethylene was injected to 18 bottles separately. Then the bottles were put into the shaker and were oscillated for $30 \mathrm{~min}$. The supernatant was harvested by centrifugation at $12,000 \mathrm{~g}$ for $15 \mathrm{~min}$ and $1 \mathrm{uL}$ liquid was taken by the micro sampler, and the Gas Chromatography analysis was carried out for 3 times.

Results and discussion

Fig. 1 is the standard curve of epoxyethane.

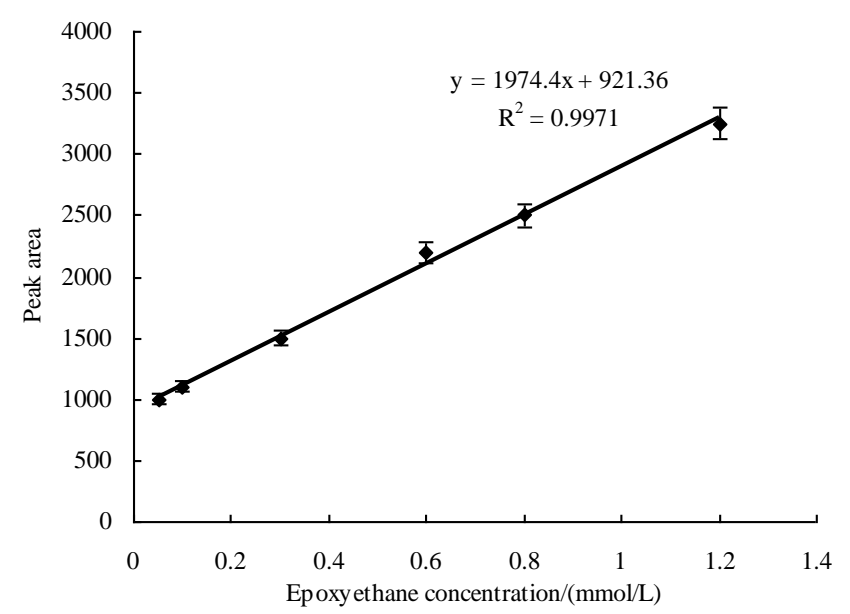

Figure 1. Standard curve of epoxyethane

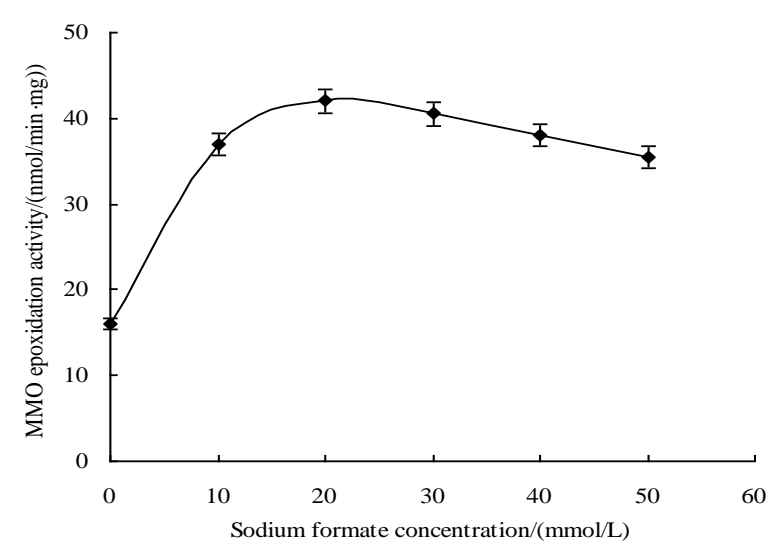

Figure 2. The effect of Sodium formate on ethylene epoxidative activity of MMO

Sodium formate is a good electron donor for the epoxidation of ethylene. The effect of sodium formate on ethylene epoxidative activity of MMO is shown in Fig. 2. The results show that sodium formate solution can obviously increase the ethylene epoxidative activity of MMO. Formate is the metabolite of methane-oxidizing bacteria. It can be directly converted into carbon dioxide and water catalyzed by the formate dehydrogenase. In addition, the reaction can produce NADH. When formate concentration is $20 \mathrm{mmol} / \mathrm{L}$, the ethylene epoxidation catalytic activity of $\mathrm{MMO}$ is 43.63 $\mathrm{nmol} /(\mathrm{min} \cdot \mathrm{mg})$. The higher concentration of formate can inhibit the enzyme. On the other hand, the higher salt concentration in the environment can also bring some toxic influence to the cells, which will cause the cell loss. 


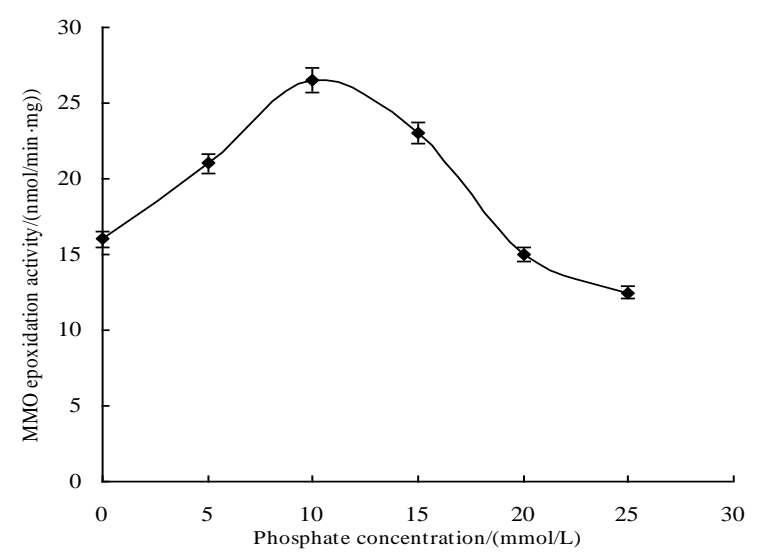

Figure 3. The effect of Phosphate concentration on ethylene epoxidative activity of MMO

The effect of phosphate concentration on ethylene epoxidative activity of MMO is shown in Fig. 3. When the concentration of phosphate increases, ethylene epoxidative activity of MMO increases at first and then decreases. After adding $10 \mathrm{mmol} / \mathrm{L}$ phosphate, MMO activity reaches the maximum which is $26.93 \mathrm{nmol} /(\mathrm{min} \cdot \mathrm{mg})$. The phosphate can increase the permeability of the cell membrane, it make MMO and ethylene contact greatly. However, when phosphate concentration is too high, ethylene epoxidative activity is lower than that of no phosphate addition. This may be ascribed to the toxicity of phosphate for methanotrophic cells.

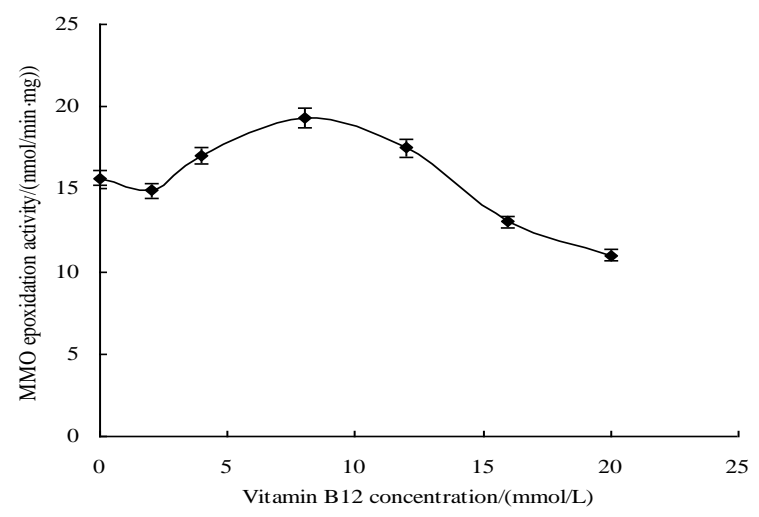

Figure 4. The effect of Vitamin B12 concentration on ethylene epoxidative activity of MMO

The effect of vitamin B12 concentration on ethylene epoxidative activity of MMO is shown in Fig. 4. When vitamin $\mathrm{B} 12$ is $8 \mathrm{mg} / \mathrm{L}$, the ethylene epoxidative activity of $\mathrm{MMO}$ is $19.31 \mathrm{nmol} /(\mathrm{min} \cdot \mathrm{mg})$ which is the maximum. MMO activity is $15.67 \mathrm{nmol} /(\mathrm{min} \cdot \mathrm{mg})$ without vitamin B12. When vitamin B12 concentration is too high, ethylene epoxidative activity of MMO is lower than that of no Vitamin B12. It has been shown that excess vitamin B12 inhibit MMO activity. So trace amounts of vitamin B12 can make MMO activity increase slightly.

\section{Conclusions}

The feasibility of removing ethylene with methanotrophs has been studied. We focus on how to improve the ethylene epoxidative activity of MMO. When formate concentration is $20 \mathrm{mmo} / \mathrm{L}$, the ethylene epoxidative activity of MMO is $43.63 \mathrm{nmol} /(\mathrm{min} \cdot \mathrm{mg})$. Phosphate makes cell permeability rise, MMO and ethylene can contact greatly. After adding $10 \mathrm{mmol} / \mathrm{L}$ phosphate, MMO activity reaches the maximum which is $26.93 \mathrm{nmol} /(\mathrm{min} \cdot \mathrm{mg})$. By the Addition of vitamin B12 as exogenous growth factors, the result confirms that ethylene epoxidative activity of MMO is not improved. When vitamin B12 is $8 \mathrm{mg} / \mathrm{L}$, ethylene epoxidative activity of $\mathrm{MMO}$ is $19.31 \mathrm{nmol} /(\mathrm{min} \cdot \mathrm{mg})$ which is the maximum. When vitamin B12 concentration is too high, ethylene epoxidative activity of MMO is 
lower than that of no vitamin B12 addition. The reason may be that vitamin $\mathrm{B} 12$ is toxic to methanotrophs or cobalt ions may affect the MMO dinuclear activity center. It remains to be further studied.

\section{Reference}

[1] Hanson R S, Hanson T E. Methanotrophic bacteria[J]. Microbiol Res, 1996, 60(2): 439-471.

[2] Mosier A, Schimel D. Methane and nitrous oxide fluxes innative, fertilized and cultivated grasslands[J]. Nature ( Lon2don), 1991, 350: 330-332.

[3] Vermeiren, F Devlieghere, M Van Beest, et al. Developments in the active packaging of foods[J]. Trends Food Sci Technol, 1999, 10(3): 77-86.

[4] PENG Li-tao, JIANG Yue-ming, JIANG Wei-bo. Advances in ethylene control of horticultural crops[J]. Food Science, 2002, 23(7) : 132-136.

[5] Semrau J D, DiSpirito A A, Yoon S. Methanotrophs and copper[J]. FEMS microbiology reviews, 2010, 34(4): 496-531.

[6] Wise M G, McArthur J V. Methylosarcina fibrata gen. nov. ,sp. nov. and Methylosarcina quisquiliarum sp. nov. , novel type I methanotrophs[J]. Int. J. Syst. Evol. Microbiol, 2001, 51: 611-621.

[7] MURRELL J C, GILBERT B,MCDONALD I R.. Molecular biology and regulation of methane monooxygenase[J]. Arch Microbiology, 2000, 173: 325-332.

[8] SMITH D D, DALTON H. Solubilisation of methane monooxygenase from methylococcus capsulatus (Bath) [J]. Eur J Biochem, 1989, 182: 667-671.

[9] Romanovskaia V A, Sokolov I G, Malashenko I R. Ethanol formation by methane-utilizing bacteria at ethane co-metabolism [J]. Mikrobiol Z. 2002, 64(1): 48-56.

[10] Yub R A, Guis M, Amor M B, et al. Espression of ACC oxidase antisense gene inhibits ripening of cantaloupe melon fruits[J]. Nat Biotechnol, 1996, 14(7): 862.

[11] Mahews H. Genetic transfoymation of strswberry. Stable itegration of a gene to control biosynthesis of ethylene[J]. In vitro Cell Dev Biol Plant, 1995, 31(1): 36.

[12] JIANG Jian-jun, WANG Lin-shan. The application technology of food additive[M]. Beijing: Science Press, 2004. 